\title{
Using Wave and Energy Theories on Quantitative Control of Postprandial Plasma Glucose via Optimized Combination of Food and Exercise (Math-Physical Medicine)
}

\author{
Gerald C. Hsu* \\ Medical Research Scientist, EclaireMD Fondation, 7 Oak Haven Way, Woodside, CA 94062 USA. \\ *Corresponding Author: Gerald C. Hsu, Medical Research Scientist, EclaireMD Fondation, 7 Oak \\ Haven Way, Woodside, CA 94062 USA.
}

\section{INTRODUCTION}

The author used math-physical medicine to research and identify the quantitative relationship between postprandial plasma glucose (PPG) and the combined effect of food and exercise. Applying both wave theory and energy theory from physics on his big data analytics, he can further observe and analyze the PPG waveforms in detail. And then, he was able to derive certain practical rules to guide how to control PPG via fine tuning the combination of food and exercise.

\section{MeTHOdS}

Food is the most important factor of PPG, but it is also difficult to regulate eating habits. The author created an artificial intelligence (AI) based software to collect and analyze his meal data by utilizing optical physics, signal processing, mathematics, statistics, and machine learning. He then developed a PPG prediction model based on his big food bank with $\sim 8$ million data. This food nutrition bank contains $6 \mathrm{M}$ food and nutrition data from the United States Department of Agriculture (USDA), 500 franchised restaurants, and his own collected 4,300 meal photos. Each meal photo links with the data, such as nation, meal location, food type, menu or dish name, and its nutritional ingredients. The system can estimate consumed carbs /sugar amount and then predict PPG value prior to eating.

Above and beyond his daily four glucose measurements by finger-piercing and test strip for more than 8-years (a total of 12,000 glucose data for 3,000 days), he recently collected 14,400 glucose data during 180 days by applying a Libre sensor on his upper arm (from $5 / 5 / 2018$ to $10 / 31 / 2018$ with $\sim 80$ measurements per day). Since there are only four data per day using the finger-piercing method, he could only analyze the glucose wave over a period of time. Now, with 80 data per day, he has sufficient data to observe the glucose wave within a particular day to investigate its characters and variance.

He then applied both wave theory from electronics engineering and energy theory from mechanical engineering to analyze these newly obtained glucose waveforms and their associated energy levels. As a result, he was able to understand the extensive damage done to the human organs due to high glucose value and its associated massive energy.

$\mathrm{He}$ used both optical physics and signal processing techniques to develop the PPG prediction model. At first, he has established the hidden link between light and glucose. He then decomposed the measured PPG wave into 19 sub-waveforms. Next, he calculated each sub-wave's contribution to the total glucose wave. He then re-integrated these 19 subwaveforms to a combined waveform, which is the predicted PPG wave. He compared the predicted PPG value against the measured PPG value to get their accuracy rate. Through a dedicated research and refinement, he has finally reached to a $99.9 \%$ linear accuracy. During this analysis period (6/1/2015 $10 / 1 / 2017$ ), he identified that food occupies $\sim 39 \%$ of the contribution margin, while exercise occupies $\sim 41 \%$. Therefore, the combination of food and exercise contributes about $80 \%$ of the PPG formation.

In a separate analysis period of fasting plasma glucose (FPG) from 1/15/2016 to $9 / 15 / 2017$, he identified that body weight occupies $>80 \%$ of FPG formation. The size of the food portion has a direct impact on our body weight. Therefore, food plays a vital role in both FPG and PPG. However, in early 2018, when he started to investigate glucose from the energy point of 
Using Wave and Energy Theories on Quantitative Control of Postprandial Plasma Glucose via Optimized Combination of Food and Exercise (Math-Physical Medicine)

view, he suddenly realized weight is merely a physical representation of internal energy exchange in the human body. The energy infusion derives mainly from food, whereas energy diffusion comes from exercise and activities. It is important to avoid having energy imbalance (disequilibrium); otherwise, the excessive (left-over) energy will damage one'sinternal organs.

In addition to his collected $\sim 1.5 \mathrm{M}$ metabolism data and $\sim 8 \mathrm{M}$ food/meal data, he further collected additional 14,400 glucose data for 174 days $\quad(5 / 5 / 2018-10 / 25 / 2018 \quad$ with 80 measurements /day). He observed and analyzed these glucose waveforms and phenomena in detail by using wave and energy theories from physics and engineering and also calculated their associated energy levels. Finally, he has identified some practical ways to either avoid the buildup of ultra-high amplitude of glucose wave or how to wear off its massive energy quickly.

\section{RESULTS}

He selected a period of 1,194 days (6/1/20159/7/2018) with 3,721 meals (including snacks) and $\sim 100,000$ data for his analysis. There were 86 airline meals consumed during his 94 trips during this period. The summary results are listed by both nation and meal location; then, they were sorted by PPG value with the format of PPG (mg/dL) \& carbs/sugar (gram).

By Nation

\begin{tabular}{|l|r|c|c|c|}
\hline Nation & No. Meals & PPG (mg/dL) & Carbs/Sugar (grams) & Nation \% \\
\hline USA & 2148 & 117.6 & 13.0 & $58 \%$ \\
\hline Taiwan & 679 & 123.0 & 14.9 & $18 \%$ \\
\hline Japan & 294 & 117.4 & 15.6 & $8 \%$ \\
\hline Canada & 292 & 115.1 & 14.3 & $8 \%$ \\
\hline Other Nations & 222 & 123.7 & 19.8 & $6 \%$ \\
\hline Airlines & 86 & 137.3 & 26.0 & $2 \%$ \\
\hline Grand Total & 3721 & 119.1 & 14.5 & $100 \%$ \\
\hline
\end{tabular}

Figure 1: Nation Summary Results

In summary, he had $58 \%$ of meals within the USA and $42 \%$ in other nations.

Airlines: cross nations (137.3, 26.0g) Other Nations (123.7, 19.8g)

Taiwan (123.0, 14.9g), USA (117.6, 13.0g), Japan (117.4, 15.6g), Canada (115.1, 14.3g)

By Location

\begin{tabular}{|l|r|c|c|c|}
\hline Eating Place & No. Meals & PPG (mg/dL) & Carbs/Sugar (grams) & Place \% \\
\hline Home Cooking & 2158 & 113.8 & 11.5 & $59 \%$ \\
\hline Chain Restaurant & 450 & 121.2 & 11.7 & $12 \%$ \\
\hline Individual Restaurant & 967 & 127.7 & 20.6 & $27 \%$ \\
\hline Supermarket & 59 & 130.2 & 25.7 & $2 \%$ \\
\hline Airlines & 86 & 137.3 & 26.0 & $2 \%$ \\
\hline Grand Total & 3634 & 121.9 & 14.8 & $100 \%$ \\
\hline
\end{tabular}

Figure 2: Eating Location Summary Results

In summary, he had $59 \%$ of meals at home and $41 \%$ outside.

Airlines (137.3, 26.0g), Supermarket (130.3, 25.7g), Individual Restaurant (127.7, 20.6g), Chain Restaurant (121.2, 11.7g), Home Cooking (113.8, 11.5g)

There are a few practical ways to achieve the above-mentioned purposes:

[1] Use an AI-based tool to predict the PPG value before eating meal;

[2] Don't consume more than 30-40 grams of carbs/sugar per each meal which will push the PPG peak to exceed 160-180 mg/dL;
[3] Walk at least 15-20 minutes (1,500-2,000 steps) after each meal, 4,000 steps for severe diabetes patients. If overeating, try to stretch the walking time over a longer period, e.g. rest 5 minutes after walking 10 minutes and then repeat.

[4] Avoid snacks in between meals and try not to have them too close to the next meal. 
Using Wave and Energy Theories on Quantitative Control of Postprandial Plasma Glucose via Optimized Combination of Food and Exercise (Math-Physical Medicine)

Otherwise, the glucose curve will turn into a "Himalaya mountain" shape that contains massive energy. Post-meal walking can bring down the peak quickly and turn the glucose curve into a "Grand Canyon" shape with much less associated energy, even with a high peak.

He developed a few computational formulas and practical tips as stated below to "fine-tune" both energy infusion by food and energy diffusion through exercise in order to "wear-off" the excessive energy generated by glucose. He also identified a reasonable energy perturbation range $(-7 \%$ to $+17 \%)$.

(1) Predict the PPG level before eating meal.
(2) Don't eat $>30$ grams of carbs/sugar per each meal because it can push the PPG peak above $160 \mathrm{mg} / \mathrm{dL}$.

(3) Walk a minimum of 1,500 steps after each meal or 4,000 steps for severe diabetes patients. More rigorous exercise can bring down the PPG peak value but stretching the walking period can wear off the energy to make the glucose waveform look like a "Grand Canyon" shape, which still has a high amplitude with much less energy.

(4) Don't eat snacks too close to the next meal in order to avoid the building of a glucose waveform similar to the "Himalaya Mountain" shape which indicates massive energy.

\begin{tabular}{|l|l|r|c|c|c|}
\hline By Nation & Within Each Nation & No. Meals & PPG (mg/dL) & Carbs/Sugar (grams) & Place \% \\
\hline & National Total & 2148 & 117.6 & 13.0 & $100 \%$ \\
\hline & Home Cooking & 1389 & 113.7 & 11.3 & $65 \%$ \\
\hline & Chain Restaurant & 265 & 120.1 & 11.0 & $12 \%$ \\
\hline & Individual Restaurant & 453 & 125.6 & 18.2 & $21 \%$ \\
\hline & Supermarket & 40 & 132.4 & 27.1 & $2 \%$ \\
\hline & National Total & 679 & 123.0 & 14.9 & $100 \%$ \\
\hline & Home Cooking & 355 & 117.4 & 11.7 & $52 \%$ \\
\hline & Chain Restaurant & 87 & 124.0 & 9.0 & $13 \%$ \\
\hline & Individual Restaurant & 237 & 129.9 & 22.6 & $35 \%$ \\
\hline & National Total & 294 & 117.4 & 15.6 & $100 \%$ \\
\hline & Home Cooking & 151 & 110.7 & 11.6 & $51 \%$ \\
\hline & Chain Restaurant & 64 & 124.2 & 17.1 & $22 \%$ \\
\hline & Individual Restaurant & 71 & 133.8 & 25.4 & $24 \%$ \\
\hline & Supermarket & 8 & 126.1 & 20.9 & $3 \%$ \\
\hline & National Total & 292 & 115.1 & 14.3 & $100 \%$ \\
\hline & Home Cooking & 220 & 110.0 & 10.8 & $75 \%$ \\
\hline & Chain Restaurant & 17 & 122.1 & 19.3 & $6 \%$ \\
\hline & Individual Restaurant & 55 & 129.4 & 25.8 & $19 \%$ \\
\hline & National Total & 222 & 123.7 & 19.8 & $100 \%$ \\
\hline & Home Cooking & 43 & 116.2 & 15.2 & $19 \%$ \\
\hline & Chain Restaurant & 17 & 116.3 & 15.9 & $8 \%$ \\
\hline & Individual Restaurant & 151 & 127.3 & 21.6 & $68 \%$ \\
\hline & Supermarket & 11 & 125.1 & 24.2 & $5 \%$ \\
\hline & Total & 86 & 137.3 & 26.0 & $100 \%$ \\
\hline & Airline In-flight Food & 48 & 134.2 & 26.4 & $56 \%$ \\
\hline & Airline Lounge Food & 14 & 150.4 & 35.3 & $16 \%$ \\
\hline & & & & \\
\hline
\end{tabular}

Figure 3: Detailed Meal Analysis

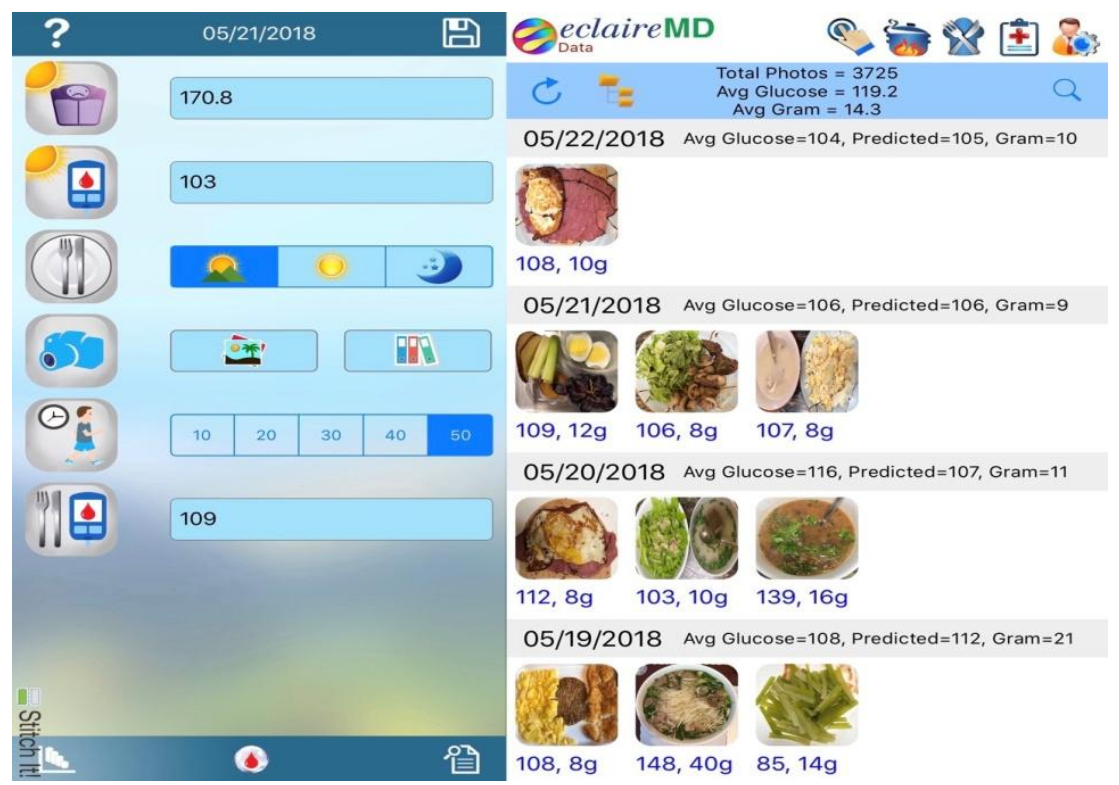

Figure 4: Using AI Glucometer to Predict Glucose Value via Meal Photos 
Using Wave and Energy Theories on Quantitative Control of Postprandial Plasma Glucose via Optimized Combination of Food and Exercise (Math-Physical Medicine)

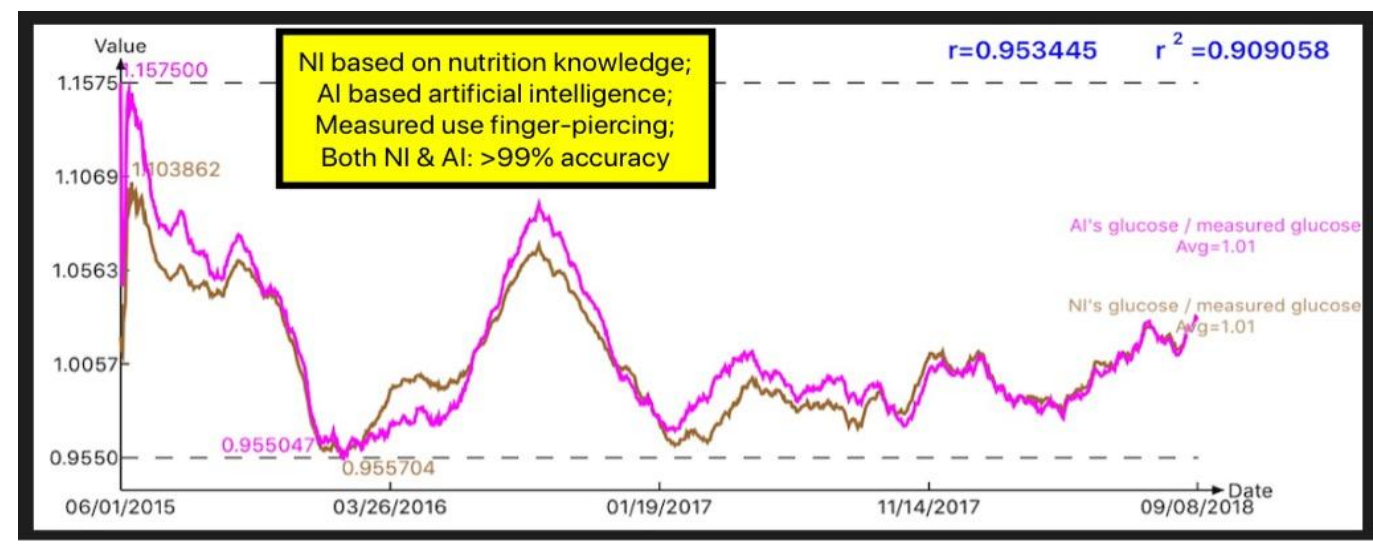

Figure 5: Accuracy Comparison between Nutritional Intelligence (NI) and Artificial Intelligence (AI)

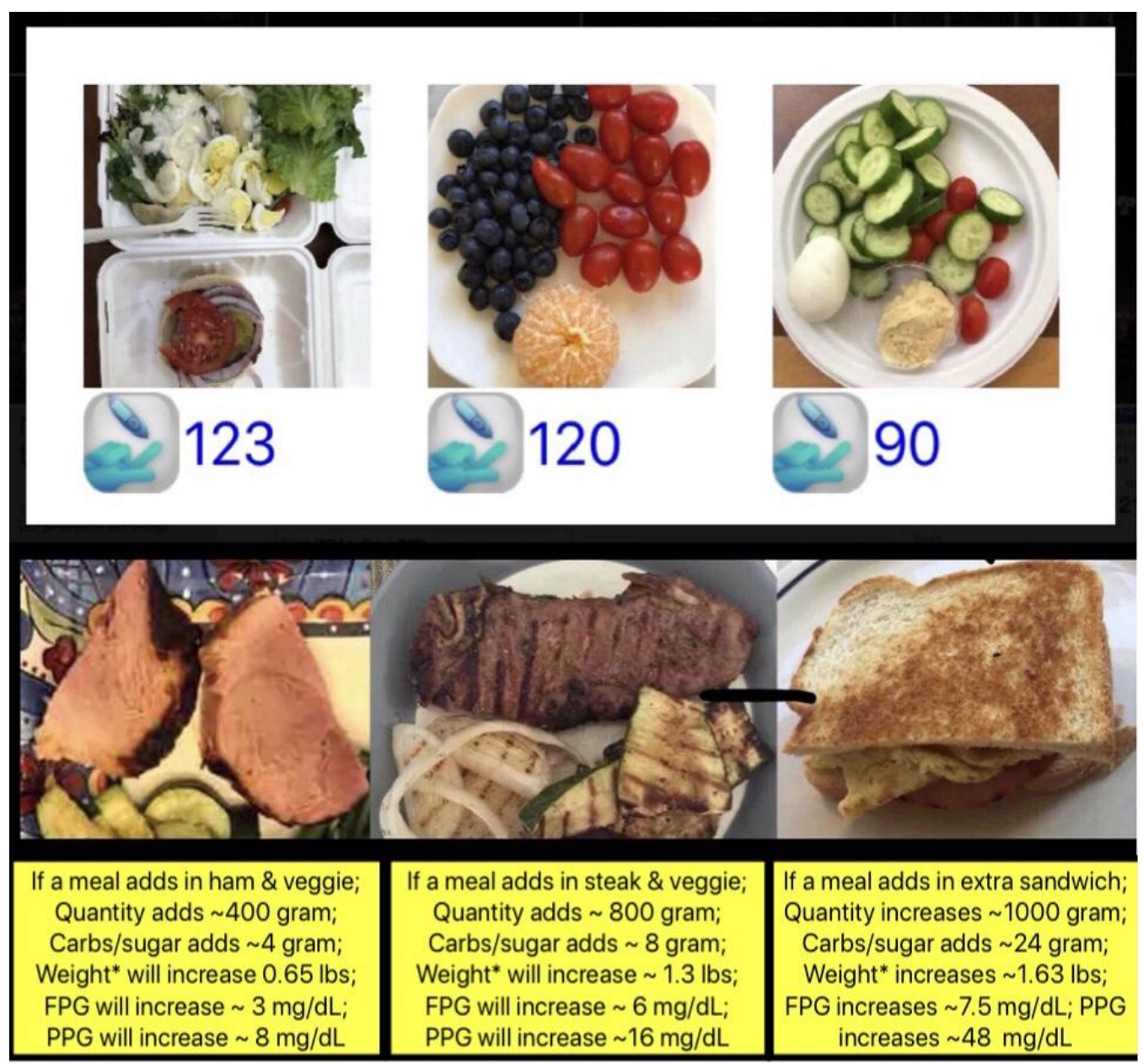

Figure 6: Samples of meals with glucose values

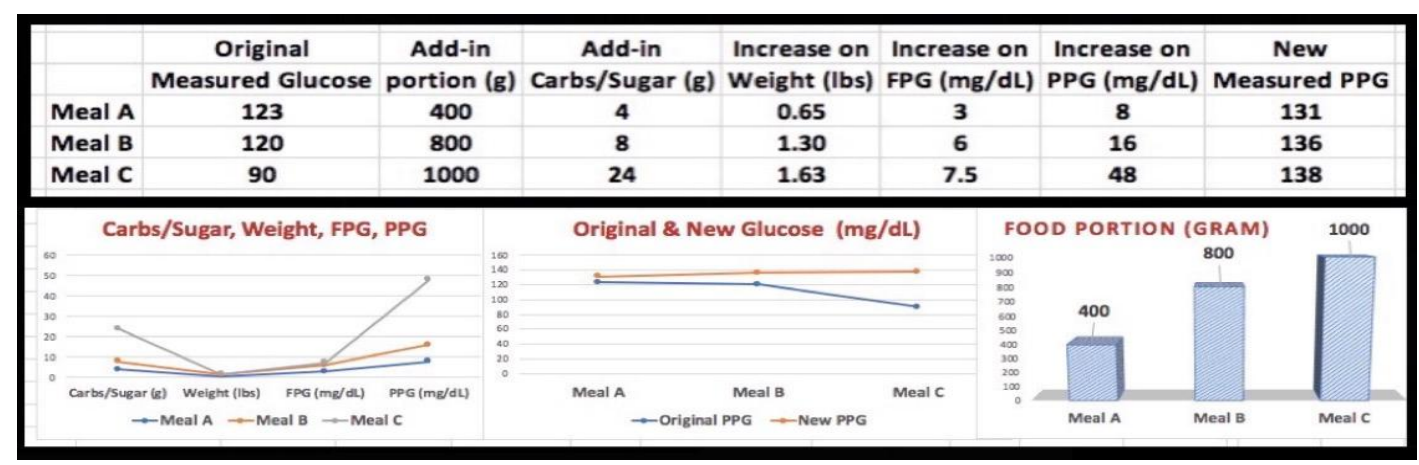

Figure 7: Original and New Glucose $(\mathrm{mg} / \mathrm{dL})$ 
Using Wave and Energy Theories on Quantitative Control of Postprandial Plasma Glucose via Optimized Combination of Food and Exercise (Math-Physical Medicine)

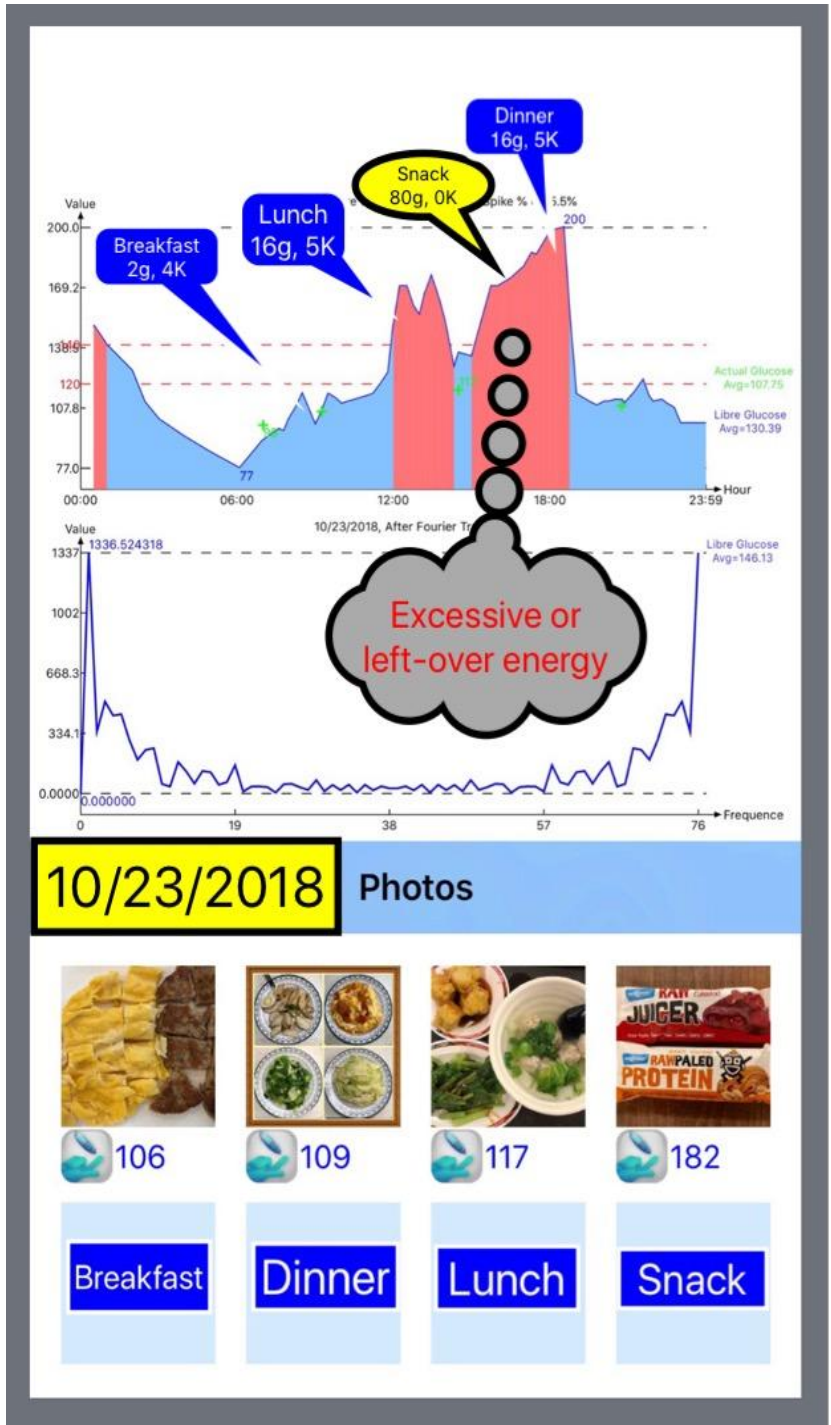

Figure 8: Excessive or leftover energy

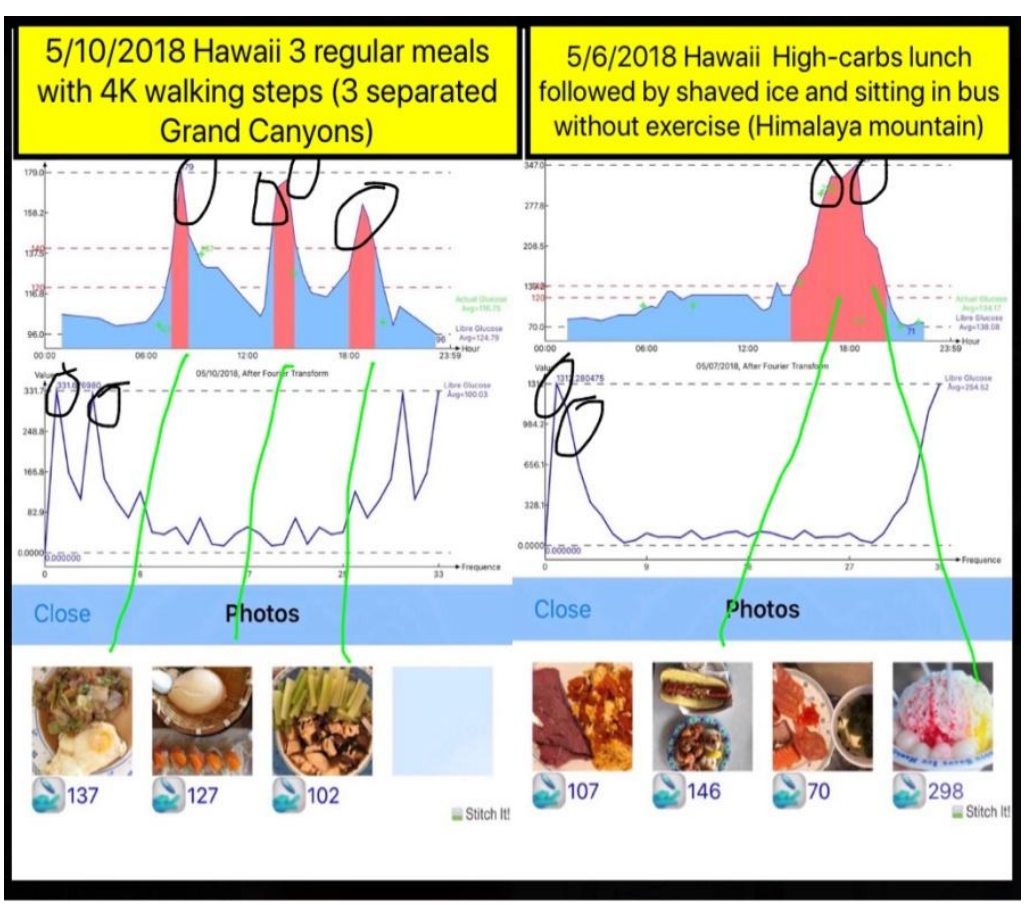

Figure 9: Hawaiian meals showing Grand Canyon and Himalayan charts 
Using Wave and Energy Theories on Quantitative Control of Postprandial Plasma Glucose via Optimized Combination of Food and Exercise (Math-Physical Medicine)

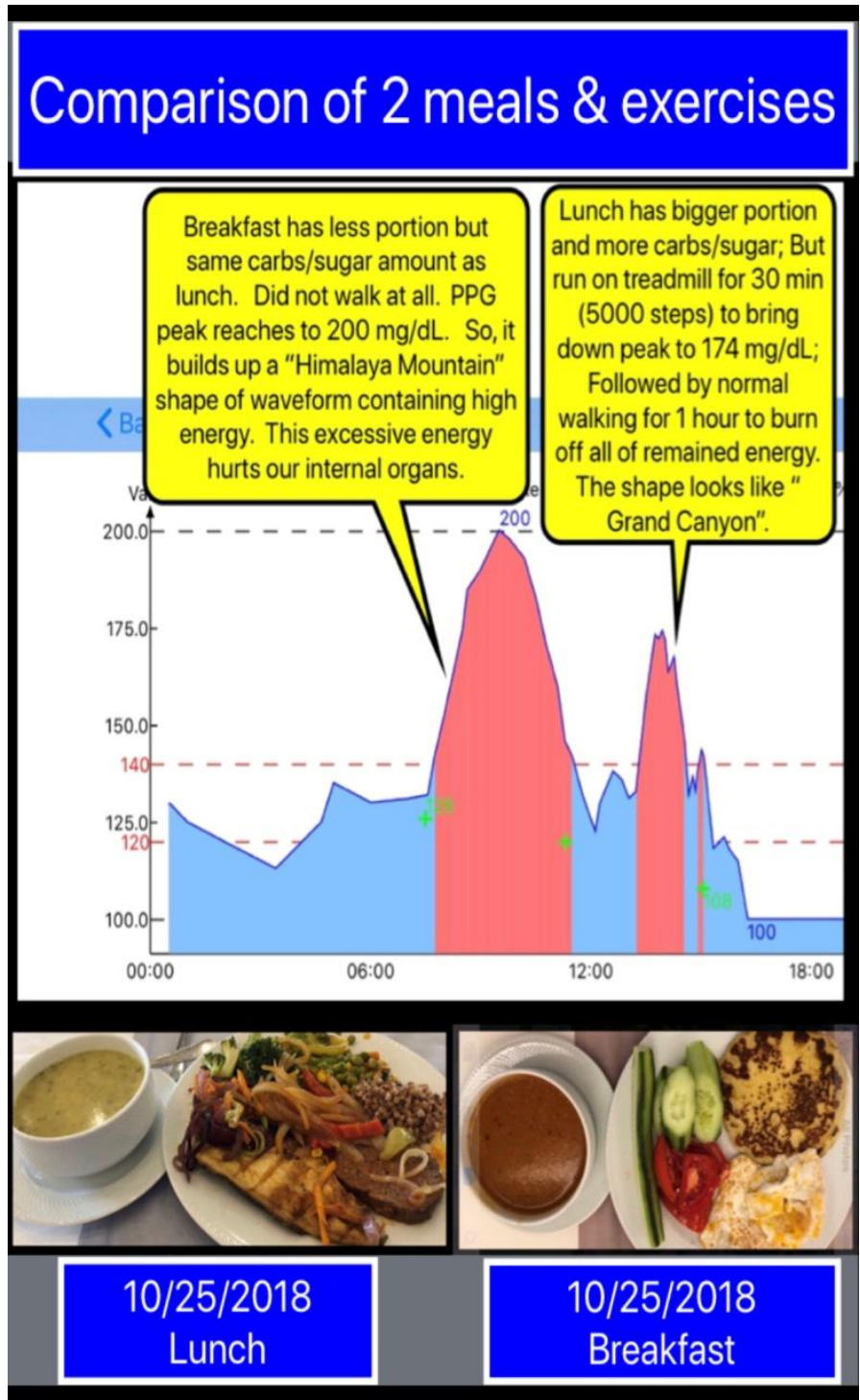

Figure 10: A comparison of two meals and exercise

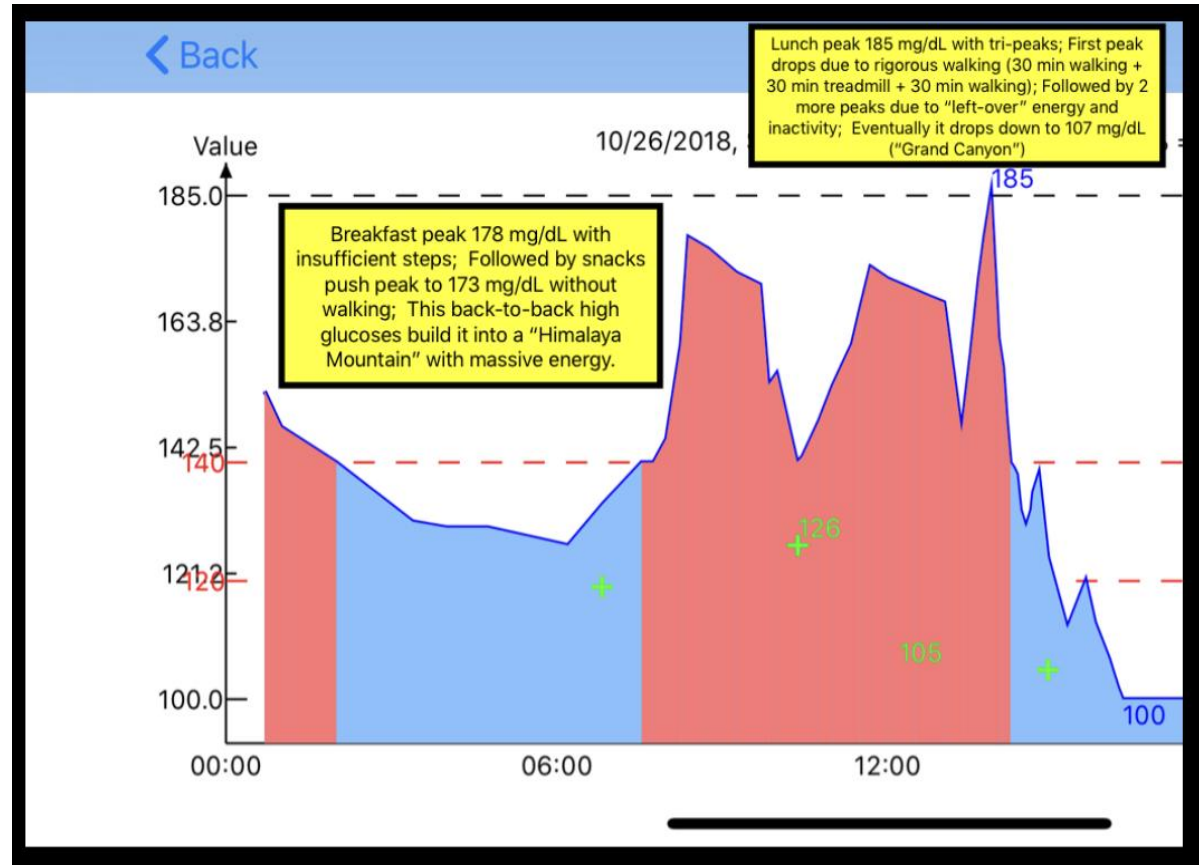

Figure 11: A comparison between meals reflecting Himalaya Mountain and Grand Canyon 
Using Wave and Energy Theories on Quantitative Control of Postprandial Plasma Glucose via Optimized Combination of Food and Exercise (Math-Physical Medicine)

\section{CONCLUSION}

The analysis (Figures 3, 4, 5) and predicted PPG model (99.9\% accuracy) assisted the author to lower his PPG from $279 \mathrm{mg} / \mathrm{dL}$ to $119 \mathrm{mg} / \mathrm{dL}$.

His practical method regarding the control of energy infusion through food intake and energy consumption by post-meal walking can guide type 2 diabetes (T2D) patients to achieve the best control of their PPG conditions.

His method and practical tips can "fine-tune" the energy infusion caused by food and energy diffusion (post-meal walking) and provide guidance to T2D patients inachieving a better PPG control.

\section{REFERENCES}

[1] Hsu, Gerald C. (2018). Using Math-Physical Medicine to Control T2D via Metabolism Monitoring and Glucose Predictions. Journal of Endocrinology and Diabetes, 1(1), 1-6. Retrieved from http:/ /www. kosmos publishers. com/wpcontent/uploads/ 2018/06/JEAD-101-1.pdf

[2] Hsu, Gerald C. (2018, June). Using MathPhysical Medicine to Analyze Metabolism and Improve Health Conditions. Video presented at the meeting of the 3rd International Conference on Endocrinology and Metabolic Syndrome 2018, Amsterdam, Netherlands.
[3] Hsu, Gerald C. (2018). Using Signal Processing Techniques to Predict PPG for T2D. International Journal of Diabetes \& Metabolic Disorders, 3(2),1-3. Retrieved from https:// www.opastonline.com/wp-content/uploads/201 8/06/using-signal-processing-techniques-to-pre dict-ppg-for-t2d-ijdmd-18.pdf

[4] Hsu, Gerald C. (2018). Using Math-Physical Medicine and Artificial Intelligence Technology to Manage Lifestyle and Control Metabolic Conditions of T2D. International Journal of Diabetes \& Its Complications, 2(3), 1-7. Retrieved from http://cmepub.com/ pdfs/ usingmathphysical-medicine-and-artificial-intelligencetechnology-to-manage-lifestyle-and-controlmetabolic-conditions-of-t2d-412. pdf

[5] Hsu, Gerald C. (2018). A Clinic Case of Using Math-Physical Medicine to Study the Probability of Having a Heart Attack or Stroke Based on Combination of Metabolic Conditions, Lifestyle, and Metabolism Index.

[6] Journal of Clinical Review \& Case Reports, 3(5), 1-2. Retrieved from https://www. opastonline. com/wp-content/uploads/ 2018/07/ a-cliniccase-of-using-math-physical-medicine-to-study -the-probability-of-having-a-heart-attack-orstroke-based-on-combination-of-metabolicconditions-lifestyle-and-metabolism-index-jcrc2018.pdf

Citation: Gerald C. Hsu, "Using Wave and Energy Theories on Quantitative Control of Postprandial Plasma Glucose via Optimized Combination of Food and Exercise (Math-Physical Medicine)", International Journal of Research Studies in Medical and Health Sciences. 2020; 5(4): 03-09.

Copyright: (c) 2020 Gerald C. Hsu, This is an open-access article distributed under the terms of the Creative Commons Attribution License, which permits unrestricted use, distribution, and reproduction in any medium, provided the original author and source are credited. 